\title{
POLA ASUH DALAM KELUARGA DAN PENGARUHNYA PADA PENDIDIKAN KARAKTER
}

\author{
Oleh \\ ${ }^{1}$ Nurliani Siregar; ${ }^{2}$ Hasahatan Hutahaean*; ${ }^{3}$ Emia Kesya Ruliati Ginting; ${ }^{4}$ Minar \\ Aprinita Meka; ${ }^{5}$ Regita Depari; ${ }^{6}$ Romiana Hasugian; ${ }^{7}$ Tiur Mida Tambunan; ${ }^{8}$ Wahyuni \\ Sitepu \\ ${ }^{1}$ Universitas HKBP Nommensen; ${ }^{2345678}$ STT Sumatera Utara \\ Correspondence Author* hasea2014@gmail.com
}

\begin{abstract}
This research looks for patterns of educating children to the residents of Pintubesi hamlet who adhere to Hinduism. Th e pattern of educating children is a process carried out to improve and support the physical, emotional, social, financial, and intellectual development of a child from infancy to adulthood. And the research finds out how to educate children in Hinduism and the similarities or differences that appear with adherents of other religions there. From initial observations, it is suspected that all residents with their respective religious backgrounds in Pintubesi have the same pattern in educating children. The study used a quantitative approach by triangulating interviews, distributing questionnaires, and discussing together. the results stated that as parents must be able to educate children to grow up to be good children (suputra) and useful for others. In addition, parents must also be able to instill positive values in children so that the child's growth pattern is in accordance with what is taught by Hinduism. From a cultural perspective, there is no visible difference in parenting among the Karo people in Pintu Besi Village, even though they have different religions.
\end{abstract}

Keywords: educating children, Hinduism, pattern of educating, Karo people

\section{PENDAHULUAN}

Anak adalah masa depan dunia, baik tidaknya kehidupan berikutnya adalah bergantung pada penyiapan dan kesiapan anak. Pola mendidik anak adalah suatu proses yang ditujukan untuk meningkatkan serta mendukung perkembangan fisik, emosional, sosial, finansial, dan intelektual seorang anak sejak bayi hingga dewasa (Suteja, 2017). Hal ini menjadi tanggungjawab orangtua sebab orangtua merupakan guru pertama untuk anak dalam mempelajari banyak hal, baik secara akademik maupun kehidupan secara umum. Tugas pertama dan penting orangtua diantaranya harus menunjukkan keteladanan yang baik kepada anak-anak mereka dan setiap orangtua perlu punya dasar pola didik yang baik agar anak bisa tumbuh menjadi pribadi yang baik. Tentu untuk mencapai hal tersebut orang tua harus memperisapkan waktu khusus demi mendidik anaknya (Susilawati, 2020, 192). Masing-masing orangtua tentu berhak memutuskan pola asuh yang tepat untuk buah hati mereka. Yang perlu diingat, pola mendidik pada anak akan memengaruhi kepribadian dan karakter anak di masa mendatang hingga si anak mempunyai satu konsep diri sendiri (Utami \& Asih, 2017, 126). Anak merupakan anugerah, dalam pandangan agama Hindu seorang anak

Pola Asuh dalam Keluarga dan Pengaruhnya pada Pendidikan Karakter

Universitas HKBP Nommensen dan STT Sumatera Utara

Nurliani Siregar; Hasahatan Hutahaean; Emia Kesya Ruliati Ginting; Minar Aprinita Meka; Regita Depari; Romiana Hasugian; Tiur Mida Tambunan; Wahyuni Sitepu 
merupakan pewaris sekaligus penyelamat bagi orang tua dan para leluhur. Begitu pentingnya peran dan kedudukan seorang anak, maka setiap keluarga tentunya mengharapkan anak yang suputara, seorang berbakti kepada oran tua, leluhur, serta taat kepada ajaran agama (Sanjaya, 2019). Namun, tidak dapat dipungkiri terkadang anak memiliki kelambanan baik sisi fisik dan psikis. Kelambanan ini bisa dari berbagai factor atau penyebab. Salah satu penelitian menyebut bahwa factor social memberi pengaruh terhadap pertumbuhan dan perkembangan anak. Karena itu Samio menyarankan agar orang tua mendorong anak memberikan keleluasaan bagi anak dalam bergaul dan bersosial, meski tetap memberikan pengawasan agar anak tidak salah memilih komunitas pergaulannya (Samio, 2018, 39). Peneliti melihat bahwa faktor dominan yang mempengaruhi keterlambatan pada anak ialah pola asuh orang tua. Khususnya pola asuh orang tua yang kurang tepat bagi anak usia dini di masa perkembangannya.

Pendidikan karakter yang utama dan pertama bagi anak adalah lingkungan keluarga. Pendidikan seharusnya memberikan dasar bagi pendidikan anak mengenai proses sosialisasi dan kehidupannya utama dan bertanggung jawab mendidik anak-anaknya. Pendidikan yang diberikan orangtua anak. Keluarga sebagai satuan unit sosial terkecil merupakan lingkungan pendidikan yang paling anak demikian juga sebaiknya. Keberhasilan pembentukan karakter pada anak ini salah satunya di masyarakat. Pola asuh orangtua yang baik akan membawa dampak baik bagi perkembangan pribadi, cinta kasih dan hubungan yang penuh kasih sayang. Ragam tipe pola asuh orangtua yang penting dalam membentuk sistem interaksi anak yang berwatak dan berkarakter baik,

yang intim dan berlangsung lama ditandai oleh loyalitas dipengaruhi oleh tipe pola asuh orang tua dalam mendidik anak. Orangtua memegang peranan permisif; serta yang keempat, acuh tak acuh. Masing-masing pola asuh ini mempunyai dampak bagi terdiri dari empat macam, diantaranya yaitu Pertama, otoritatif; Kedua, otoritarian; dan Ketiga, tua yang cenderung menganggap sederajat hak dan kewajiban anak dibanding dirinya karena pada pola asuh otoritatif. Hal ini, disebabkan bahwa dalam pola asuh tipe otoritatif ini bercirikan orang perkembangan anak. Adapun pola asuh yang terbaik dalam pembentukan karakter anak adalah tipe anak. Setiap agama memberikan ajaran yang penuh kasih sayang dalam mengasuh anak. Karena orang tua tentunya menginginkan agar anaknya tidak hanya menjadi sosok yang cerdas, tetapi juga taat beragama Bagi Suryandari pola asuh orang tua adalah merupakan suatu cara terbaik yang ditempuh orang tua, dalam mendidik anak sebagai perwujudan dari rasa tanggung jawab kepada anak. Dalam penelitiannya Suryandiri mengungkap bahwa pola asuh sejak dini terhadap anak akan menolongnya untuk terhindar dari kenakalan-kenakalan pada masa lebih tua kelak (Suryandari, 2020, 28). Dalam ajaran agama Hindu, orangtua mendambakan agar anak-anaknya tumbuh menjadi anak suputra. Lalu, apa makna dari anak suputra yang merupakan pola mendidik dari umat Hindu? Anak suputra adalah anak yang berbudi pekerti luhur, cerdas, bijaksana, dan membanggakan keluarga. Anak suputra ini akan mengangkat harkat dan martabat orang tua. Kata "putra" itu sendiri berasal dari bahasa Sanskerta yang pada mulanya berarti kecil atau yang disayang. Kelahiran anak suputra ini merupakan tujuan ideal dari setiap perkawinan dalam ajaran Hindu. Jika orang tua tidak mendidik anaknya dengan

Pola Asuh dalam Keluarga dan Pengaruhnya pada Pendidikan Karakter

Universitas HKBP Nommensen dan STT Sumatera Utara Nurliani Siregar; Hasahatan Hutahaean; Emia Kesya Ruliati Ginting; Minar Aprinita Meka; Regita Depari; Romiana Hasugian; Tiur Mida Tambunan; Wahyuni Sitepu 
baik, maka anak tersebut akan menjadi anak kuputra, yang merupakan perlawanan dari suputra.

Kitab Nitisastra dan Kitab Veda merupakan rujukan utama umat Hindu dalam mendidik Nitisastra lebih jauh menurut Gandhi dalam kitab tersebut memberikan ajaran tentang bagaimana seharusnya mengasuh anak agar Si Kecil bisa menjadi seorang anak suputra, yaitu anak harus diberikan bentuk kedisiplinan dari orangtuanya (Gandhi, 1996). Hal ini di lakukan agar kelak anak tidak menjadi anak yang pelawan, menjadi anak yang patuh dan melakukan kebaikan. Dalam Nitisastra Sloka 3.18, disebutkan: "Asuhlah anak dengan memanjakannya sampai berumuh lima tahun, berikanlah hukuman (pendidikan disiplin) selama sepuluh tahun berikutnya. Kalau ia sudah dewasa (sejak remaja) didiklah dia sebagai teman." Oleh karena itu pendidikan dan pembinaan anak menuju saputra merupakan hal yang sangat penting. Menurut Setyowahyudi bahwa pendidikan itu sebaiknya dimulai sejak anak dalam fase usia dini. Tentu dimulai dengan menggunakan berbagai media yang sesuai dengan usia mereka (Setyowahyudi, 2020, 33) Usia ini terbukti sangat menentukan kemampuan anak dalam mengembangkan potensinya.

Artayasa mengaitkan adanya dampak dari pola asuh orang tua serta memperlakukan anak, dan mendidik, membimbing, dan mendisiplinkan sera melindungi anak dalam mencapai proses kedewasaan, hingga kepada upaya pembentukan norma-norma yang diharpakan oleh masnyarakat pada umumnya. Kegiatan tersebut dapat dilaksanakan dengan percakapan-percakapan sehari-hari sembari memberi nilai karakter pada anak (Artayasa, 2021, 101). Banyak nilai yang dapat dipetik dari pendidikan anak (Sanjaya, 2019, 48). Pada kitab

agama Hindu. Nurlensi misalnya memaparkan bahwa dalam pembentukan karakter menyatakan bahwa revolusi mental dalam nilai-nilai pendidikan Hindu diperlukan untuk membentuk karakter bangsa khususnya dan secara nyata telah membentuk dan membangun jati diri umat Hindu semenjak dalam kandungan (garbhata), sampai akhirnya terlahir sebagai bayi (sisu), mampu menjadi generasi muda (yuva atau yowana) yang andal (suputra ca suputri), yakni pemuda dan pemudi (sisya ca mahasisya) yang berkualitas. Tidak ketinggalan tiga ajaran satya (mitra, laksana, semaya) sangat kuat dalam mendidik pada nilai luhur bangsa (Nurlensi, 2019, 24). Demikian juga hingga dimasa keluarga (grahastha) sampai ke masa tua (werdha) telah dibekali dengan nilai-nilai luhur agama Hindu sehingga dapat tampil sebagai umat Hindu yang berkarakter mulia, berbudhi luhur, berkepribadian dan sejenisnya, yang dilahirkan dari penerapan konsep pendidikan Hindu yang berlangsung seumur hidup.

Penelitian Susilawati di Palu menunjukkan bahwa peran orang tua memiliki peran penting dalam menanamkan nilai-nilai etika dan budi pekerti bagi anak (Susilawati, 2020, 192) agar anak tampak tertib, santun dan disenangi di tengah masyarakat serta berguna kelak bagi bangsa dan Negara. Asmat Purba memberikan perhatian terhadap pendidikan anak sangat didominasi peran orang tua khususnya dalam kurun pandemik (Purba, 2020). Bukan saja tentang pendidikan karakter namun terhadap tanggung jawab pendidikan sekolah menjadi bagian tidak terpisahkan terhadap orang tua nara didik yang bersekolah dari rumah, dimana pada saat bersamaan orang tua juga bekerja dari rumah (selama work from home, wfh). Peneliti melihat hal ini menjadi demikian penting untuk ditelaah ketika anak-anak

Pola Asuh dalam Keluarga dan Pengaruhnya pada Pendidikan Karakter

Universitas HKBP Nommensen dan STT Sumatera Utara Nurliani Siregar; Hasahatan Hutahaean; Emia Kesya Ruliati Ginting; Minar Aprinita Meka; Regita Depari; Romiana Hasugian; Tiur Mida Tambunan; Wahyuni Sitepu 
hidup di tengah-tengah keberagaman agama dalam suku yang sama. Di dusun Pintu besi terdapat empat agama (Protestan, Khatolik, Islam dan Hindu), dimana mayoritas penduduknya (95\%) suku Karo (Desa, 2020).

\section{Hipotesa}

Dari observasi lapangan yang sudah dilakukan, peneliti melihat adanya kesamaan pola hidup pada masyrakat didusun pintu besi, Desa Lau Rakit, Kec. STM Hulu, Kab. Deli Serdang-SUMUT diantaranya pemeluk agama Kristen dan agama Hindu. Hal ini tampak nyata misalnya dalam mendidik anak, pola adat budaya diantara kedua pemeluk agama. Karena itu, diduga kesamaan suku batak Karo diantara kedua pemeluk agama itu telah memberikan dukungan untuk tercapainya pola mendidik anak yang baik dan benar. Dengan demikian, hipotesis ini memerlukan penelitian lanjutan untuk menemukan data di lapangan dan maknanya bagi pola mendidik Anak bagi warga desa tersebut maupun untuk seluruh bangsa Indonesia.

\section{Metode Penelitian}

Metode Penelitian ini adalah metode kualitatif dengan model pendekatan studi kasus. Dengan sebuah model yang memfokuskan eksplorasi (sistem terbatas) atas satu kasus-kasus ataupun sebagaian kasus secara terperinci dengan menggali data yang mendalam dan beragam sumber informasi yang kaya akan konteks dilakukan untuk penggalian informasi dengan partisipasi pihak-pihak yang bersangkutan dan partisipasi penelitian dan lokasi penelitian agar tercapai tujuan untuk mendapatkan informasi tentang masalah yang diteliti. Beragam sumber informasi yang kaya akan konteks dilakukan untuk menggali data. Metode pengumpulan data menggunakan metode wawancara, observasi dan angket.

Oleh sebab itu maka peneliti melakukan penelitian wawancara (Darmalaksana, 2020) melakukan metode penelitian metode kualitatif kepada masyarakat Desa pintu Besi, kec. STM Hilir, kabupaten Deliserdang, SUMUT, yang beragama Hindu, namun memiliki suku kebudayaan Karo. Untuk menggali Informasi bagaimana orangtua dalam mendidik anaknya menurut agama dan kebudayaannya dari warga agaa Hindu. Dengan penelitian ini akan diketahui bagaimana persepsi masyarakat beragama Hindu di Pintu Besi, Kec. STM Hilir terhadap ajaran agamanya dalam mendidik anak mereka serta berinteraksi dengan sesama yang berbeda agama, budaya, dan bahasa. Serta bagaimana orangtua beragama Hindu mengajarkan nilai-nilai agama (kitab \& ajaran suputra) kepada anak-anak mereka.

Peneliti akan merangkum hasil wawancara baik terstruktur dan non terstruktur dengan pengelompokkan yang dibutuhkan seturut hipotesa di atas. Atas izin dari narasumber, dan pemimpin agama di Pintubesi, maka nama-nama yang ada selama wawancara diizinkan untuk disebut demi keperluan laporan (artikel) penelitian ini.

\section{PEMBAHASAN}

\section{Temuan Penelitian}

Dari hasil wawancara dengan Tokoh-tokoh Agama beserta masyarakat yang ada di Desa Pintu Besi khususnya Umat Hindu. Ketika peneliti menanyakan tentang pola mendidik anak, disampaikan bahwa selama ini mendidik anak berjalan dengan kondusif meskipun berbeda agama namun sama suku Karo yang ada di Desa tersebut. Meskipun banyak penganut agama yang berbeda namun itu bukan menjadi sebuah landasan untuk menimbulkan konflik, tetapi saling

Pola Asuh dalam Keluarga dan Pengaruhnya pada Pendidikan Karakter

Universitas HKBP Nommensen dan STT Sumatera Utara Nurliani Siregar; Hasahatan Hutahaean; Emia Kesya Ruliati Ginting; Minar Aprinita Meka; Regita Depari; Romiana Hasugian; Tiur Mida Tambunan; Wahyuni Sitepu 
menghargai satu dengan yang lain terlihat dalam kerukunan umat beragama yang sudah jelas dilihat oleh penulis. Terlebih prinsip hidup bagi umat Hindu ialah "Aku adalah Kamu dan Kamu adalah Aku" itu merupakan semboyan yang sudah jarang terdengar di berbagai kalangan masyarakat. Dari prinsip tersebutlah peneliti mengetahui cara mendidik anak bagi kehidupan masyarakat umat Hindu yang ada di Desa Pintu Besi memberikan dampak yang positif bagi sesama. Demikian hasil dari observasi yang sudah diperoleh peneliti melalui wawancara, menyebarkan angket.

Tabel 1. Pengertian Anak

\begin{tabular}{|c|c|}
\hline Nr.S & Jawaban/Tanggapan \\
\hline $\begin{array}{l}\text { Karma } \\
\text { Perangi } \\
\text { n-angin }\end{array}$ & $\begin{array}{l}\text { Anak merupakan pewaris/mewarisi } \\
\text { keturunan, dan keturunan itu yang } \\
\text { akan membawa keluarga ke } \\
=\text { moksa (surga). Dalam pemikiran } \\
\text { agama Hindu, jika tidak ada } \\
\text { keturunan dari pasangannya maka } \\
\text { mereka bisa menikah lagi lebih dari } \\
\text { satu kali baik itu istri atau suami } \\
\text { sampai mereka juga bisa } \\
\text { memperoleh keturunan/anak dan } \\
\text { perbuatan tersebut tidak salah } \\
\text { asalkan adanya keturunan yang } \\
\text { diperoleh karena anak begitu } \\
\text { sangat penting bagi umat agama } \\
\text { Hindu. }\end{array}$ \\
\hline $\begin{array}{l}\text { Iwayan } \\
\text { Sura }\end{array}$ & $\begin{array}{l}\text { Dalam mendidik anak harus ada } \\
\text { ditekankan pola agar anak tidak } \\
\text { menyakiti dan tidak membunuh } \\
\text { mahkluk yang tidak bersalah dan } \\
\text { yang paling utama adalah kejujuran } \\
\text { yaitu jujur kepada } \\
\text { Tuhan,manusia,dan alam. Selain } \\
\text { itu, anak diajarkan untuk tidak } \\
\text { bertengkar dan tidak berbohong. }\end{array}$ \\
\hline $\begin{array}{l}\text { Ida } \\
\text { Yanti } \\
\text { Br. } \\
\text { Bangun }\end{array}$ & $\begin{array}{l}\text { Dalam mendidik anak, orang tua } \\
\text { tetap mendukung anak bergaul } \\
\text { dengan suku dan agama yang lain } \\
\text { karena pergaulan dengan diluar }\end{array}$ \\
\hline
\end{tabular}

\begin{tabular}{|l|l|}
\hline & $\begin{array}{l}\text { agama Hindu bisa menambah } \\
\text { pengetahuan anak tersebut Jelas } \\
\text { anak begitu sangat istimewa bagi } \\
\text { kehidupan setiap orang tua, } \\
\text { sehingga apapun yang dibutuhkan } \\
\text { anak pasti dicukupi oleh setiap } \\
\text { orang tua. }\end{array}$ \\
\hline Malem & $\begin{array}{l}\text { Sebagai orang tua tidak terlalu } \\
\text { Kembatasi pergaulan dengan } \\
\text { agama lain agar anak tersebut dapat } \\
\text { mengetahui perbedaan dan nilai } \\
\text { toleransi. Jadi,bisa dikatakan bahwa } \\
\text { istimewa nya anak terlihat dengan } \\
\text { cara mendidik orang tua yang tidak } \\
\text { mengekang anak dan bebas bergaul } \\
\text { dengan siapapun asalkan mengarah } \\
\text { kepada kebaikan. }\end{array}$ \\
\hline
\end{tabular}

Cat; Nr.S= nara sumber. Demikian seterusnya

Tabel 2 .Pengajaran Yang Baik Kepada Seorang Anak

\begin{tabular}{|l|l|}
\hline \multicolumn{1}{|c|}{ Nr.S } & \multicolumn{1}{|c|}{ Jawaban/Tanggapan } \\
\hline $\begin{array}{l}\text { Karma } \\
\text { Perangi } \\
\text { n-angin }\end{array}$ & $\begin{array}{l}\text { Dalam umat Hindu diajarkan untuk } \\
\text { saling mengasihi dan boleh bergaul } \\
\text { dengan siapapun tidak ada sloka } \\
\text { menentang hal tersebut }\end{array}$ \\
\hline $\begin{array}{l}\text { Iwayan } \\
\text { Sura }\end{array}$ & $\begin{array}{l}\text { Agama Hindu menekankan bahwa } \\
\text { Saya adalah kamu dan kamu adalah } \\
\text { saya . Dan harus saling bergaul dan } \\
\text { menyerap nilai-nilai positif dari } \\
\text { teman-teman sepergaulannya }\end{array}$ \\
\hline $\begin{array}{l}\text { Ida } \\
\text { Yanti } \\
\text { Br. }\end{array}$ & $\begin{array}{l}\text { Tidak membatasi pergaulan anak } \\
\text { dan tetap mendukung setiap } \\
\text { pergaulan anak }\end{array}$ \\
\hline $\begin{array}{l}\text { Malem } \\
\text { Krina }\end{array}$ & $\begin{array}{l}\text { Anak bebas bergaul dengan } \\
\text { siapapun asalkan pergaulan yang } \\
\text { mengarah kepada kebaikan }\end{array}$ \\
\hline
\end{tabular}

Tabel 3. Pendidikan Yang Paling Ditanamkan Oleh Orang Tua Dari Agama Atau Lebih Kesukuan

\begin{tabular}{|l|l|}
\hline \multicolumn{1}{|c|}{ Nr.S } & \multicolumn{1}{c|}{ Jawaban/Tanggapan } \\
\hline Karma & $\begin{array}{l}\text { Pendidikan yang paling ditekankan } \\
\text { Perangi } \\
\text { orang tua yang ada di Desa Pintu } \\
\text { n-angin }\end{array}$ \\
\hline
\end{tabular}

Pola Asuh dalam Keluarga dan Pengaruhnya pada Pendidikan Karakter Universitas HKBP Nommensen dan STT Sumatera Utara
Nurliani Siregar; Hasahatan Hutahaean; Emia Kesya Ruliati Ginting; Minar Aprinita Meka; Regita Depari; Romiana Hasugian; Tiur Mida Tambunan; Wahyuni Sitepu 


\begin{tabular}{|l|l|}
\hline & $\begin{array}{l}\text { kepada Agama Hindu dan Suku } \\
\text { Karo. Tapi yang lebih ditekankan } \\
\text { ialah kejujuran yang diajarkan oleh } \\
\text { Agama Hindu. }\end{array}$ \\
\hline $\begin{array}{l}\text { Iwayan } \\
\text { Sura }\end{array}$ & $\begin{array}{l}\text { Lebih menekankan kepada Agama } \\
\text { Hindu karena kebaikan dan } \\
\text { kejujuran harus diberikan pada saat } \\
\text { mendidik dan mengasuh anak. }\end{array}$ \\
\hline $\begin{array}{l}\text { Ida } \\
\text { Yanti } \\
\text { Br. }\end{array}$ & $\begin{array}{l}\text { Pendidikan lebih ditekankan kepada } \\
\text { Agama Hindu dan Suku Karo karena } \\
\text { sama-sama mengajarkan kebaikan. }\end{array}$ \\
\hline $\begin{array}{l}\text { Malem } \\
\text { Krina }\end{array}$ & $\begin{array}{l}\text { Dalam mendidik anak paling } \\
\text { ditekankan ialah keduanya, karena } \\
\text { tidak boleh melupakan suku dan } \\
\text { tidak boleh membelakangkan agama. }\end{array}$ \\
\hline
\end{tabular}

Tabel 4. Karakter Yang Ditanamkan Dalam Mendidik Anak

\begin{tabular}{|l|l|}
\hline \multicolumn{1}{|c|}{ Nr.S } & \multicolumn{1}{|c|}{ Jawaban/Tanggapan } \\
\hline $\begin{array}{l}\text { Karma } \\
\text { Perangi } \\
\text { n-angin }\end{array}$ & $\begin{array}{l}\text { Karakter yang ditanamkan oleh } \\
\text { orang tua dalam mendidik anak ialah } \\
\text { kejujuran dan kebaikan }\end{array}$ \\
\hline $\begin{array}{l}\text { Iwayan } \\
\text { Sura }\end{array}$ & $\begin{array}{l}\text { Lebih menekankan kepada } \\
\text { Kejujuran terlebih jujur kepada } \\
\text { Tuhan,Sesama, dan Alam }\end{array}$ \\
\hline $\begin{array}{l}\text { Ida } \\
\text { Yanti } \\
\text { Br. } \\
\text { Bangun }\end{array}$ & $\begin{array}{l}\text { Sifat tidak memilih teman walaupun } \\
\text { berbeda suku dan agama karakter } \\
\text { yang ditanamkan hanya bersifat baik } \\
\text { dan saling menghargai }\end{array}$ \\
\hline $\begin{array}{l}\text { Malem } \\
\text { Krina }\end{array}$ & Pendidikan moral dan budi pekerti \\
\hline
\end{tabular}

Tabel 5. Kegiatan Yang Dilaksanakan Oleh Umat Hindu Berhubungan Dengan Mendidik Anak

\begin{tabular}{|c|c|}
\hline Nr.S & Jawaban/Tanggapan \\
\hline $\begin{array}{l}\text { Karma } \\
\text { Perangi } \\
\text { n-angin }\end{array}$ & $\begin{array}{l}\text { Kegiatan yang dilaksanakan oleh } \\
\text { Agama Hindu yang berhubungan } \\
\text { dalam mendidik anak ialah datang ke } \\
\text { pura dan belajar membaca sloka atau } \\
\text { mantra }\end{array}$ \\
\hline $\begin{array}{l}\text { Iwayan } \\
\text { Sura }\end{array}$ & $\begin{array}{l}\text { Membaca sloka/mantra dan } \\
\text { membuat kegiatan tari-tarian yang } \\
\text { sacral }\end{array}$ \\
\hline
\end{tabular}

\begin{tabular}{|l|l|}
\hline $\begin{array}{l}\text { Ida } \\
\text { Yanti } \\
\text { Br. } \\
\text { Bangun }\end{array}$ & $\begin{array}{l}\text { Membuat kelompok belajar agama di } \\
\text { setiap minggunya }\end{array}$ \\
\hline $\begin{array}{l}\text { Malem } \\
\text { Krina }\end{array}$ & $\begin{array}{l}\text { Rajin membawa anak tersebut ke } \\
\text { pura dan sering berbicara tentang } \\
\text { agama }\end{array}$ \\
\hline
\end{tabular}

\section{Pembahasan}

Agama Hindu adalah salah satu agama dari 6 Agama yang diakui di Indonesia (Mansur, 2017). Agama HINDU merupakan Agama ke-4 terbesar di Indonesia. Dalam ajaran Agama Hindu bukan hanya fokus kepada keyakinan saja, namun juga mengajarkan bagaimana cara dalam melaksanakan Kerukunan umat beragama, Pernikahan, dan Pola Mendidik anak. Karena itu, seperti telah diungkap di atas bahwa fokus dalam penelitian ini, adalah tentang pola mendidik anak dalam ajaran agama Hindu dari warga suku Karo atas persepsi pengajaran yang diterima.

Secara umum, Pola mendidik anak adalah suatu proses yang ditujukan untuk meningkatkan serta mendukung perkembangan fisik, emosional, sosial, finansial, dan intelektual seorang anak dari bayi hingga dewasa. Dalam arti mendidik sama dengan bagaimana orang tua mengasuh anak tersebut menjadi anak yang takut akan Tuhan dan menjadi anak yang baik kepada orang tua dan sesama (Caecilia Triastuti dan Ingrid Listiat, 2020).

Demikian halnya juga dengan Agama Hindu yang ada Di Desa Pintu Besi. Menurut narasumber Karma Perangin-angin pengertian anak dan cara mendidiknya adalah sama dengan apa yang dipahami oleh agama yang lain yaitu anak itu sangat begitu dibutuhkan karena, anak merupakan pewaris/mewarisi keturunan, dan keturunan itu yang akan membawa keluarga ke =moksa

Pola Asuh dalam Keluarga dan Pengaruhnya pada Pendidikan Karakter 
(surga), karena mereka berpikir dan merasa bahwa anak-anak itulah yang akan mengantar mereka ke kehidupan yang kekal yaitu dalam Bahasa Hindu Moksa (surga). Dalam pemikiran agama Hindu, jika tidak ada keturunan dari pasangannya maka mereka bisa menikah lagi lebih dari satu kali baik itu istri atau suami sampai mereka memperoleh keturunan/anak dan perbuatan tersebut tidak salah asalkan adanya keturunan yang diperoleh karena anak begitu sangat penting bagi umat agama Hindu (Astawa, 2018).

Menurut Saudari Ida Yanti Br.Bangun Dalam mendidik anak, orang tua tetap mendukung anak bergaul dengan suku dan agama yang lain karena pergaulan dengan diluar agama Hindu bisa menambah pengetahuan anak tersebut Jelas anak begitu sangat istimewa bagi kehidupan setiap orang tua, sehingga apapun yang dibutuhkan anak pasti dicukupi oleh setiap orang tua.

Menurut Malem Krina tentang pola mendidik anak adalah, sebagai orang tua tidak terlalu membatasi pergaulan dengan agama lain agar anak tersebut dapat mengetahui perbedaan dan nilai toleransi. Jadi, bisa dikatakan bahwa istimewanya anak terlihat dengan cara mendidik orang tua yang tidak mengekang anak dan bebas bergaul dengan siapapun asalkan mengarah kepada kebaikan.

Dalam mendidik anak, tentunya bukanlah hal yang mudah. Saat memiliki anak, orang tua juga dituntut mampu untuk mengajari si anak banyak hal. Oleh karena itu, penting bagi semua pasangan untuk mengetahui beragam cara mendidik anak yang baik agar anak tumbuh menjadi seorang anak yang kelak diterima dengan mudah dilingkungannya. Anak-anak harus diajari perilaku yang baik agar bisa hidup dan bekerja dengan baik di masyarakat saat dewasa kelak (Suteja, 2017) Cara mendidik anak yang baik harus disesuaikan dengan usia anak. Semua orang tua pasti menginginkan anak yang baik dan benar dihadapan Tuhan, orang tua dan sesama. Namun,cara mendidik anak dalam agama Hindu ditanamkan nilai kejujuran dan diajarkan bagaimana agar anak tetap melaukan kejujuran disetiap aktivitas kehidupannya dan kejujuran ini menekankan anak harus jujur kepada Tuhan, jujur kepada sesama manusia, dan jujur kepada alam. Jadi, kepada Tuhan kejujuran itu ditunjukkan ke dalam sikap-sikap anak sembahyang, dan kita harus membuat hubungan yang harmonis dan melakukan kebaikan dalam bentuk persembahan buah kepada Tuhan. Dan menurut Bapak Pendeta Iwayan Sura, ada 5 pola mendidik anak yaitu:

1. Ahimsa, (tidak menyakiti,dan tidak membunuh mahkluk yang tidak bersalah)

2. Brahmacari, (berguru)

3. Satkiam, (jujur)

4. Tidak suka bertengkar (berusaha menghindari pertengkaran)

5. Astea (Melarang anak mencuri, tidak berbohong).

Dan selain kelima pola mendidik anak tersebut ada suatu organisasi yang mendukung anak untuk menjadi anak yang taat dan jujur yaitu dengan cara membuat kegiatan pasraman (berada di rumah ibadah). Dalam pasraman diajari ada beberapa hal bukan hanya tentang ilmu keagamaan tapi harus juga didampingi dengan belajar minimal anak bisa baca sloka/mantra meskipun tidak mengerti setidaknya anak tau membaca Bab-Bab yang ada dalam kitab weda. Ada juga tari-tarian sacral (tari yang hanya boleh ditunjukkan dirumah ibadat) cenderung perempuan dan musiknya tradisional. Tujuan dari pengajaran ini tidak lain hanya untuk memuja leluhur.

Pola Asuh dalam Keluarga dan Pengaruhnya pada Pendidikan Karakter

Universitas HKBP Nommensen dan STT Sumatera Utara

Nurliani Siregar; Hasahatan Hutahaean; Emia Kesya Ruliati Ginting; Minar Aprinita Meka; Regita Depari; Romiana Hasugian; Tiur Mida Tambunan; Wahyuni Sitepu 
Selain itu, Pendidikan anak dalam agama Hindu mengajarkan 3 tingkatan hidup manusia yakni: 1. Brahmacari, menuntut ilmu setinggi-tingginya dan anak tidak menikah, karena filosopinya belajarlah sampai ke negeri cina, setelah ia mendapat ilmu, maka ilmu ini diabdikan kepada masyarakat dan alam semesta. Dan bukan merusak, setelah mengabdikan diri kepada masyarakat maka anak akan mendapat harta. 2. Tak, Twan, Asi, Kamu itu adalah saya, dan dimana pun ia berada pasti banyak orang merasakan damai.

3. Aham, Brahman, Asmi, Kamu dan saya adalah Tuhan, dan sering disebut sebagai Atman, artinya dalam Agama Hindu tidak ada membeda-bedakan agama karena menurut ajaran agama Hindu, mereka yang bukan menganut Agama Hindu juga adalah diri mereka sendiri (Jayendra \& Semadi, 2020).

Dalam ajaran Agama Hindu, tidak ada perbedaan yang diajarkan antar agama dan kesukuan. Umat Hindu menganggap bahwa semua agama, suku adalah sama. Dan semua manusia itu adalah sama, maka konsep Agama Hindu adalah Saya adalah Kamu dan kamu adalah saya (Arifin, 2019). Itu merupakan hal yang sangat diinginkan oleh tiap-tiap pemeluk agama agar tidak terjadinya konflik yang dapat merusak hubungan antar suku maupun ras. Beralih ke dalam pola mendidik anak dalam suku Karo yang ada di Desa Pintu Besi, informasi yang didapat oleh peneliti ialah suku Karo mengajarkan kebaikan dan selaras dengan apa yang diajarkan oleh agama Hindu kepada setiap anak.

Karma Perangin-angin berpandangan bahwa penganut suku Karo sangat luar biasa dalam mendidik anak, alasannya menyebutkan hal tersebut adalah karena orang karo sangat antusias untuk menyekolahkan anaknya dan tetap berjuang untuk membuat Pendidikan anak nya setinggi-tinggi mungkin. Karena tanpa Pendidikan kita pasti akan dibawah dan harta yang paling tinggi ialah Pendidikan karena tidak bisa diambil oleh individu yang lain. Dengan demikian, persamaan yang sangat dominan tentang pola pengajaran mendidik anak dalam sudut pandang agama Hindu maupun Suku Karo yang ada di Desa Pintu Besi merupakan satu tujuan, gunanya untuk mengasuh anak menjadi anak yang baik atau Suputra (su-baik) yang biasa disebut oleh umat Agama Hindu.

Dalam hal ini, tidak ada perbedaan yang mendasari pandangan antara pola mendidik anak dalam Hindu maupun suku Karo karena kedua-duanya mengajarkan pola yang baik untuk masa depan dunia. Dalam agama Hindu ada 4 macam nama-nama anak yang diberikan oleh orang tua yaitu:

- Wayan

- $\quad$ Made

- Koman/Nyoman

- Ketut

Nama tersebut diberikan khas oleh umat Hindu di Bali, dan jika anak lebih dari 4 maka nama-nama anak selebihnya kembali dari Wayan dst. Demikianlah anak sangat di inginkan oleh Umat Hindu bukan hanya sebagai pewaris namun juga untuk membawa orang tua ke kehidupan yang selanjutnya karena keyakinan Agama Hindu setelah kematian maka ada kehidupan yang selanjutnya.

Untuk mendidik anak yang tidak kalah penting ialah sebuah komunikasi kepada anak, agar pola mendidik anak bisa berjalan dengan baik. Menurut data yang sudah diperoleh oleh peneliti dari narasumber, tidak sedikit dari orang tua menjawab bahwa komunikasi adalah suatu aspek yang sangat dibutuhkan untuk memperoleh Pendidikan 
dan sikap baik anak. Dari sebuah komunikasi lah berjalan Pendidikan anak tersebut. Dengan cara orang tua mempunyai waktu dengan anak, berbincang-bincang mengenai pertumbuhan dan hal-hal yang baik ditekankan oleh orang tua dan para pendidik. Meskipun, terlihat mudah namun ada juga kewalahan yang dirasakan oleh orang tua dalam mendidik anak menjadi dewasa, untuk memperoleh anak yang suputra pastinya peranan ayah dan ibu sangat dibutuhkan untuk lebih banyak lagi mengelola waktu yang maksimum kepada anak. Agar, anakanak bisa berpengaruh yang baik dan bergaul dengan suku atau agama yang lain, sehingga mencerminkan ke Hinduannya. Dari balita sampai dengan dewasa peranan orang tua adalah nomor satu untuk mendidik anak. Karena dari internal anak bisa tercermin kebaikannya kepada eksternal atau di luar lingkup keluarga anak tersebut.

\section{SIMPULAN}

Pola mendidik anak merupakan suatu upaya yang dilakukan orang tua untuk mengajarkan anak tentang hal yang baik mulai dari kecil hingga dewasa. Mengasuh anak agar tumbuh menjadi anak yang berkembang dari fisik maupun nonfisik. Dan menurut jawaban dari para narasumber yang berada di Desa Pintu Besi yang menganut Agama Hindu bersuku Karo, Pola mendidik anak sangat ditekankan dimana, keyakinan umat Hindu anak adalah bagian yang paling terutama karena anak yang akan membawa orang tua nya ke dalam moksa (surga). Seorang anak adalah harta yang paling penting dan sangat berharga. Selain itu peranan penting anak ialah untuk menjadi ahli pewaris dan mewarisi apa yang ada dari orang tuanya baik harta dll. Dalam mendidik anak, baik dalam komunikasi maupun dari setiap ajaran agama,dan suku sangat dibutuhkan untuk menunjang terbentuknya karakter yang diinginkan, dan yang paling ditekankan dalam umat Hindu ialah Kejujuran. Kejujuran adalah mengatakan hal yang sebenarnya tanpa menambahkan atau mengurangi dari apa yang yang sudah terjadi. Karena, dari sebuah kejujuran lah terpancar karakter baik seorang anak yang sudah dibina oleh orang tua dari kecil hingga bertumbuh dewasa. Dan dalam Umat Hindu konteks kejujuran ialah ketika anak jujur maka dimana pun ia berada bisa membawa damai bagi sesama. Tetapi yang sangat ditekankan dari kejujuran tersebut ialah harus terlebih dahulu Jujur kepada Tuhan, sesama, dan juga kepada alam

\section{DAFTAR PUSTAKA}

Arifin, A. Z. (2019). Toleransi dalam Agama Hindu; Aplikasi Ajaran dan Praktiknya di Pura Jala Siddhi Amertha Sidoarjo. Satya Widya: Jurnal Studi Agama, 2(2).

https://doi.org/10.33363/swjsa.v2i2.60

Artayasa, I. W. (2021). AJARAN

BHATARA SIWADALAM LONTAR ANDHA BHUWANAKAJIAN PENDIDIKAN KARAKTER. GUNA WIDYA : JURNAL PENDIDIKAN HINDU, 8(1), 101-111. https://doi.org/10.25078/gw.v8i1.1866 Astawa, I. N. S. (2018). Pola Pendidikan dalam Perspektif Pendidikan Hindu. Satya Widya: Jurnal Studi Agama, 1(1), 88-110.

https://doi.org/10.33363/swjsa.v1i1.40

Caecilia Triastuti dan Ingrid Listiat. (2020).

Pandangan ajaran iman Katolik mengenai pendidikan. Katolisitas.Org.

Darmalaksana, W. (2020). Metode Penelitian Kualitatif Studi Pustaka dan Studi Lapangan. In Pre-print Digital Library UIN Sunan Gunung Djati

Pola Asuh dalam Keluarga dan Pengaruhnya pada Pendidikan Karakter

Universitas HKBP Nommensen dan STT Sumatera Utara Nurliani Siregar; Hasahatan Hutahaean; Emia Kesya Ruliati Ginting; Minar Aprinita Meka; Regita Depari; Romiana Hasugian; Tiur Mida Tambunan; Wahyuni Sitepu 
Bandung (Vol. 1, Issue 1, pp. 1-6). http://digilib.uinsgd.ac.id/32855/1/Meto de Penelitian Kualitatif.pdf

Desa, K. (2020). Data Penduduk Laurakit (Data PC Kades; p. 12). Kantor Kepala Desa Laurakit.

Gandhi, M. . (1996). The Essence of Hinduism. Navajivan Publishing House Ahmedabad-380 014, 2(1), 241.

Jayendra, P. S., \& Semadi, G. N. Y. (2020). ESENSI ETIKA DAN MORALITAS DALAM KITAB NITI SATAKA. Kalangwan Jurnal Pendidikan Agama, Bahasa Dan Sastra, 9(2). https://doi.org/10.25078/klgw.v9i2.122 8

Mansur, S. (2017). Kerukunan dalam Perspektif Agama-Agama di Indonesia. Aqlania, 8(2). https://doi.org/10.32678/aqlania.v8i02. 1025

Nurlensi, -. (2019). PENDIDIKAN DAN NILAI NILAI MORALITAS DALAM AJARAN MAHABHARATA BAGI UMAT HINDU. Bawi Ayah: Jurnal Pendidikan Agama Dan Budaya Hindu, 8(1), 22-31. https://doi.org/10.33363/ba.v8i1.299

Purba, A. (2020). Tanggung Jawab Orang tua Kristen dalam Mendidikan Anak Menyikapi Pandemi Covid-19. EPIGRAPHE: Jurnal Teologi Dan Pelayanan Kristiani, 4(1), 86-97. https://doi.org/10.33991/epigraphe.v4i1 .148

Samio, S. (2018). Aspek - Aspek Pertumbuhan Dan Perkembangan Peserta Didik. Best Journal (Biology Education, Sains and Technology), 1(2), 36-43. https://doi.org/10.30743/best.v1i2.791

Sanjaya, P. (2019). MENDIDIK ANAK MENJADI SUPUTRA MENURUT
TEKS CANAKYA NITISASTRA.

PRATAMA WIDYA : JURNAL PENDIDIKAN ANAK USIA DINI, 3(2), 47-51.

https://doi.org/10.25078/pw.v3i2.738

Setyowahyudi, R. (2020). Pemikiran Ki

Hajar Dewantara dan Maria Montessori tentang Pendidikan Anak Usia Dini. PAUDIA : Jurnal Penelitian Dalam Bidang Pendidikan Anak Usia Dini, 9(1), 17-35. https://doi.org/10.26877/paudia.v9i1.56 10

Suryandari, S. (2020). Pengaruh Pola Asuh Orang Tua Terhadap Kenakalan Remaja. JIPD (Jurnal Inovasi Pendidikan Dasar), 4(1), 23-29. https://doi.org/10.36928/jipd.v4i1.313

Susilawati, L. R. (2020). Peran Orangtua Tunggal Dalam Menerapkan Pendidikan Agama Hindu Pada Anak. Widya Genitri : Jurnal Ilmiah Pendidikan, Agama Dan Kebudayaan Hindu, 11(3), 190-201.

https://doi.org/10.36417/widyagenitri.v $11 \mathrm{i} 3.363$

Suteja, J. (2017). DAMPAK POLA ASUH ORANG TUA TERHADAP PERKEMBANGAN SOSIALEMOSIONAL ANAK. AWLADY : Jurnal Pendidikan Anak, 3(1), 1-14. https://doi.org/10.24235/awlady.v3i1.1 331

Utami, R. R., \& Asih, M. K. (2017). Konsep Diri Dan Rasa Bersalah Pada Anak Didik Lembaga Pemasyarakatan Anak Kelas IIA Kutoharjo. Jurnal Dinamika Sosial Budaya, 18(1), 123-132. https://doi.org/10.26623/jdsb.v18i1.563

Pola Asuh dalam Keluarga dan Pengaruhnya pada Pendidikan Karakter 